Bull. Mater. Sci., Vol. 6, No. 3, July 1984, pp. 513-535. (C) Printed in India.

\title{
Analytical electron microscopy of aluminium alloys
}

\author{
T R RAMACHANDRAN*, D C HOUGHTON and J D EMBURY \\ Department of Metallurgy and Materials Science, McMaster University, Hamilton, Ontario, \\ Canada \\ *Department of Metallurgical Engineering, Indian Institute of Technology, Kanpur 208016, \\ India
}

\begin{abstract}
X-ray microanalysis and electron energy loss spectroscopy of thin foils constitute the important techniques of high resolution chemical analysis using the electron microscope. The technique of $\mathrm{x}$-ray microanalysis is discussed in this paper with particular emphasis on the study of aluminium alloys using a dedicated scanning transmission electron microscope (STEM).

The principle of determining chemical composition from observed x-ray peak intensities including the absorption of $x$-rays and beam broadening in thin foils are considered. The accuracy of peak intensity measurement and detection limits in $x$-ray microanalysis are illustrated with reference to Al-Mn alloys. The Cliff-Lorimer $(k)$ factors for manganese, iron and copper with respect to aluminium were obtained from standard samples. Identification of phases in 1100 and 1200 aluminium and $3008(\mathrm{Al}-\mathrm{Mn}-\mathrm{Zr})$ alloy were carried out from measured intensities of $x$-ray peaks. The experimental results emphasize the value of developing techniques for extracting the particles from the aluminium matrix. The transition phases formed in $\mathrm{Al}-6 \% \mathrm{Zn}-3 \% \mathrm{Mg}$ and $\mathrm{Al}-4 \% \mathrm{Cu}$ were investigated by micro-diffraction and $\mathrm{x}$-ray microanalysis.
\end{abstract}

Keywords. High resolution analysis; $x$-ray microanalysis; aluminium alloy; phase identification; metastable phases.

\section{Introduction}

High resolution chemical analysis of thin foils examined in the electron microscope is carried out by the detection and quantitative characterization of $\mathrm{x}$-rays and inelastically scattered electrons. X-ray microanalysis involves the detailed study of the energy (or wavelength) and intensity of characteristic $x$-rays while electron energy loss spectroscopy is concerned with the determination of characteristic energy losses suffered by the primary electrons as they pass through the specimen. The energy loss arises from a number of excitation processes amongst which electrons causing plasmon excitation and inner shell ionization are useful in providing chemical information. The important parameters in chemical analysis are the intensity of signals arising from the interaction of the electron beam with the specimen and the volume of the specimen from which these signals are excited. The former influences the accuracy and sensitivity of analysis while the latter determines the spatial resolution. High sensitivity and high resolution chemical analysis, therefore, requires the use of a high intensity small diameter electron probe. This is obtained by the use of a scanning attachment to the TEM or a dedicated STEM. The use of a highly convergent probe also allows the formation of microdiffraction patterns which provide crystallographic information from regions of the specimen illuminated by the probe. 


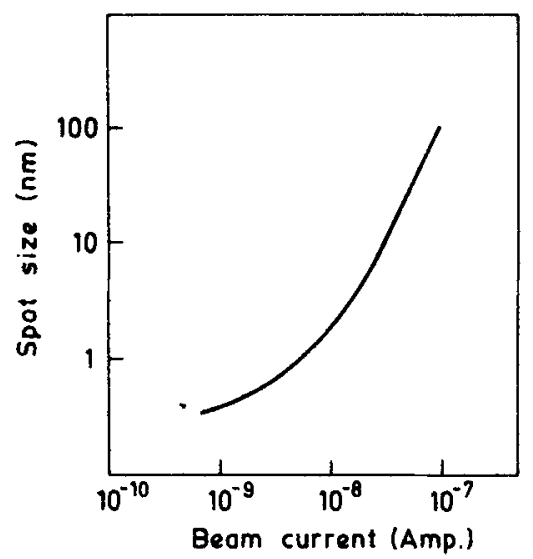

Figure 1. Relationship between beam current and beam diameter in the HBS STEM.

The dedicated STEM makes use of a field emission gun. The gun brightness of this source is high $\left(\sim 10^{13} \mathrm{~A} / \mathrm{m}^{2} / \mathrm{Sr}\right)$ and it is thus possible to form an extremely fine probe carrying enough current to excite detectable signals from the specimen. The relationship between beam current and beam diameter in the VG HB5 STEM is shown in figure 1 (Williams 1980). A probe of $\sim 2-5 \mathrm{~nm}$ diameter carries a current of $\sim 5 \mathrm{nA}$ sufficient to produce significant signal count rates. It should, theoretically, be possible to carry out chemical analysis with the same spatial resolution as the probe size. However, complications due to beam broadening (to be discussed later) affect the resolution. Microdiffraction patterns can be obtained from regions of $\sim 2 \mathrm{~nm}$ diameter using the fine probe of the dedicated STEM. This topic has been covered at length by Cowley (1982) at this conference.

The principles of $\mathrm{x}$-ray microanalysis are considered briefly in this paper followed by experimental results on phase identification and the nature of metastable phases in aluminium-base alloys.

\section{Theoretical principles}

\subsection{The ratio technique}

X-ray microanalysis involves the measurement of the intensity $I_{A}$ of a characteristic $x$-ray peak and relating it to the total number of atoms, $N_{A}$, in the irradiated volume of the specimen exciting this particular radiation. $I_{A}$ and $N_{A}$ are related by the expression (Joy 1981),

$$
I_{A}=I_{0} N_{A} Q_{A} a_{A} w_{A} F,
$$

where $I_{0}$ is the incident electron intensity, $Q_{A}$ is the scattering cross-section for x-ray excitation, $w_{A}$ is the fluorescent yield, $a_{A}$ is the ratio of the number of $K \alpha$ (or $L \alpha$ ) $x$-ray photons to the sum of the total number of photons of the $K$ (or $L$ ) series and $F$ is the detection efficiency. It is assumed in (1) that the sample is so thin that absorption and fluorescence effects can be neglected. These two assumptions constitute the thin film criterion. $N_{A}$ can be expressed in terms of the weight fraction $C_{A}$, atomic weight of $A$, $A_{A}$, thickness $t$ of the foil and $\rho$ the density of the foil-(1) can then be written as

$$
I_{A}=\frac{\text { (Constant) }\left(C_{A} Q_{A} a_{A} w_{A} F\right)}{A_{A}}
$$


If the intensities of two peaks due to elements $A$ and $B$ are simultaneously measured, the intensity ratio can be expressed by the equation,

$$
\frac{I_{A}}{I_{B}}=\frac{C_{A} Q_{A} a_{A} w_{A} A_{B}}{C_{B} Q_{B} a_{B} w_{B} A_{A}}=\frac{C_{A}}{C_{B}}\left(k_{A B}\right)^{-1},
$$

where $k_{A B}$ (commonly referred to as the Cliff-Lorimer factor) is a constant independent of sample thickness, orientation and composition but dependent on accelerating potential. Equation (3) forms the basis of the ratio technique for the determination of composition from observed intensity ratio of the peaks (Philibert and Tixier 1968; Cliff and Lorimer 1975).

\subsection{Absorption of x-rays}

The thin beryllium window, the gold contact layer and the inactive silicon layer on the detecting crystal can absorb a significant proportion of the incident $x$-rays (particularly the soft $x$-rays). A correction for absorption in the beryllium window can be made by using the expression,

$$
\frac{l_{A}}{I_{B}}=\frac{C_{A} Q_{A} w_{A} a_{A} A_{B}}{C_{B} Q_{B} w_{B} a_{B} A_{A}}\left[\frac{\exp -(\mu / \rho)_{\mathrm{Be}}^{B} \rho_{\mathrm{Be}} t_{\mathrm{Be}}}{\exp -(\mu / \rho)_{\mathrm{Be}}^{A} \rho_{\mathrm{Be}} t_{\mathrm{Be}}}\right]
$$

where $(\mu / \rho)_{\mathrm{Be}}^{A}$ and $(\mu / \rho)_{\mathrm{Be}}^{B}$ are the mass absorption coefficients of the characteristic $\mathrm{X}$-rays in beryllium, $\rho_{\mathrm{Bc}}$ is the density of beryllium and $t_{\mathrm{Be}}$ the thickness of the window (typically $7 \mu \mathrm{m}$ ).

When the thin film criterion is not valid, absorption correction can be made by the use of the expression (Tixier and Philibert 1969; Goldstein et al 1977)

$$
\frac{C_{A}}{C_{B}}=k_{A B}\left(I_{A} / I_{B}\right)_{T K}\left[\frac{(\mu / \rho)_{\mathrm{sp}}^{A}}{(\mu / \rho)_{\mathrm{sp}}^{B}}\right]\left[\frac{1-\exp -(\mu / \rho)_{\mathrm{sp}}^{B} \rho t \operatorname{cosec} \psi}{1-\exp -(\mu / \rho)_{\mathrm{sp}}^{A} \rho t \operatorname{cosec} \psi}\right]
$$

where $(\mu / \rho)_{\mathrm{sp}}^{A}$ and $(\mu / \rho)_{\mathrm{sp}}^{B}$ are the mass absorption coefficients of the characteristic $\mathrm{x}$-rays in the specimen, $\rho$ is the specimen density, $t$ is the specimen thickness and $\psi$ is the $x$-ray take-off angle. In the VG HB5 sTeM $\psi$ varies from 15 to 42 depending on the use of the non-tilt -or double tilt cartridge. The ratio $\left(I_{A} / I_{B}\right)_{T K}$ measured in thick specimens defines the constant $K_{A B}^{\text {thick }}$ which is related to $K_{A B}$ by the expression,

$$
\frac{C_{A} / C_{B}}{\left(I_{A} / I_{B}\right)_{T K}}=K_{A B}^{\text {thick }}=K_{A B}\left[\frac{(\mu / \rho)_{\mathrm{sp}}^{A}}{(\mu / \rho)_{\mathrm{sp}}^{B}}\right]\left[\frac{1-\exp -(\mu / \rho)_{\mathrm{sp}}^{B} \rho t \operatorname{cosec} \psi}{1-\exp -(\mu / \rho)_{\mathrm{sp}}^{A} \rho t \operatorname{cosec} \psi}\right]
$$

The ratio of $K_{A B}^{\text {thick }}$ to $K_{A B}$ is plotted in figure 2 for the compounds $\mathrm{Al}_{6} \mathrm{Mn}, \mathrm{Al}_{2} \mathrm{Cu}$ and $\mathrm{Al}_{3} \mathrm{Fe}$ using the data for mass absorption coefficients from Heinrich (Heinrich 1966). The absorption correction is significant when the thickness exceeds $\sim 200 \mathrm{~nm}$ and also for low take-off angle.

\subsection{Beam broadening effects}

The spatial resolution for $\mathrm{x}$-ray microanalysis is influenced by the probe size and the broadening of the probe in the specimen. Goldstein et al (1977) have considered elastic scattering of a point source of electrons by atomic nuclei at the middle of the foil and 


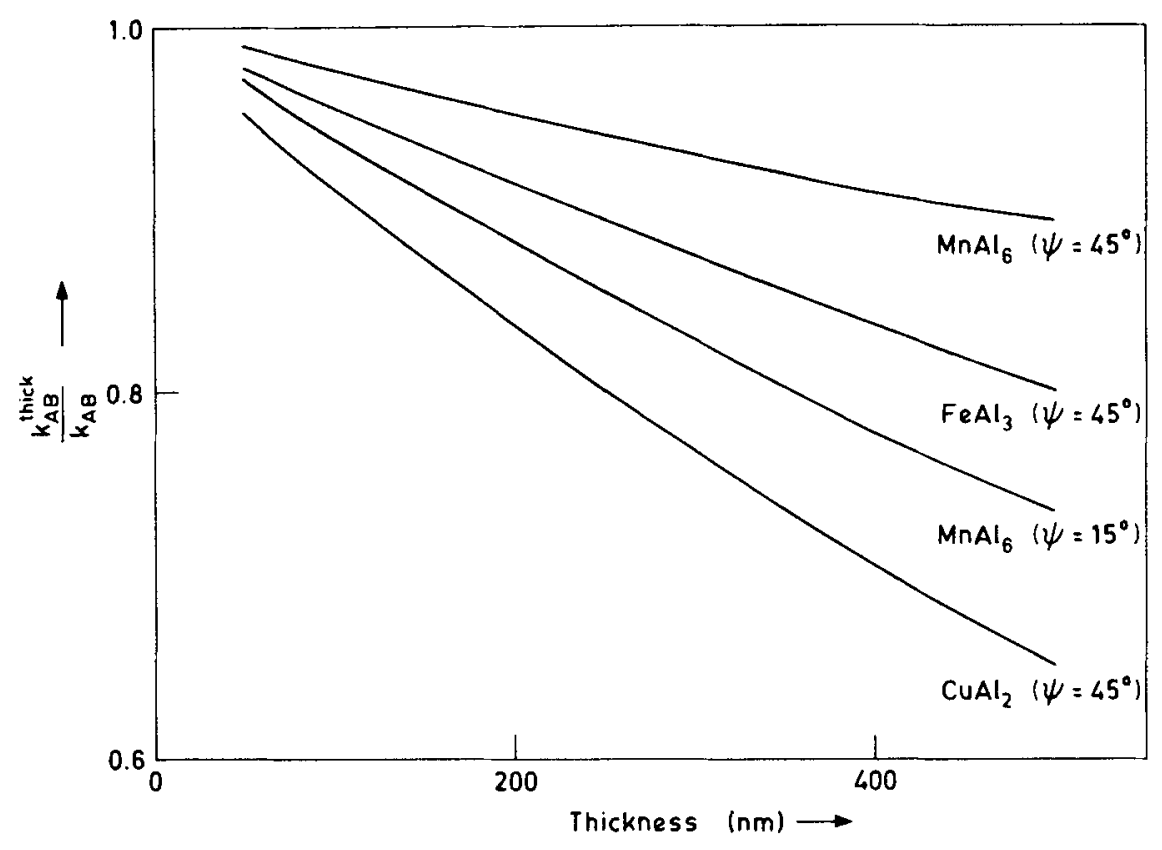

Figure 2. Relationship between $K_{A B}^{\text {thick }} / K_{A B}$ and thickness of the foil for $\mathrm{Al}_{6} \mathrm{Mn}, \mathrm{Al}_{3} \mathrm{Fe}$ and $\mathrm{Al}_{2} \mathrm{Cu}$. The effect of varying the take off angle is illustrated for $\mathrm{Al}_{6} \mathrm{Mn}$.

arrived at the following expression for beam broadening $(b)$

$$
b=625(Z / E)(\rho / A)^{1 / 2} t^{3 / 2}
$$

where $b$ and $t$ are in $\mathrm{cm}$ and $Z$ is the atomic number. A plot of beam spread against thickness is shown in figure 3 for aluminium. When the specimen thickness exceeds $200 \mathrm{~nm}$, the spatial resolution for chemical analysis is $\sim 30 \mathrm{~nm}$. It is, therefore, clear that the advantage of using a fine probe as in the STEM may be counteracted by the use of relatively thick specimens. Beam spread has also been determined by using MonteCarlo calculations (Keyser 1979) involving the simulation of individual electron trajectories. The results obtained are in excellent agreement with those predicted in (7) when the specimen thickness is less than $100 \mathrm{~nm}$.

\subsection{Precision and detection limits}

The error in estimating the net intensity of an x-ray peak, $I_{A}^{n}$, can be expressed by the standard deviation, $\sigma\left(I_{A}^{n}\right)$, as

$$
\sigma\left(I_{A}^{n}\right)=\left(I_{A}^{t}+I^{b}\right)^{1 / 2}
$$

where $I_{A}^{t}$ represents the total intensity collected in a predefined energy window and $I^{b}$ is the background intensity. The relative error $\varepsilon$ for $95 \%$ confidence limit can be expressed as

$$
\varepsilon=\frac{2 \sigma\left(I_{A}^{n}\right)}{I_{A}^{n}}=2\left[\frac{1}{I_{A}^{n}}\left(1+\frac{2}{P / B}\right)\right]^{1 / 2},
$$




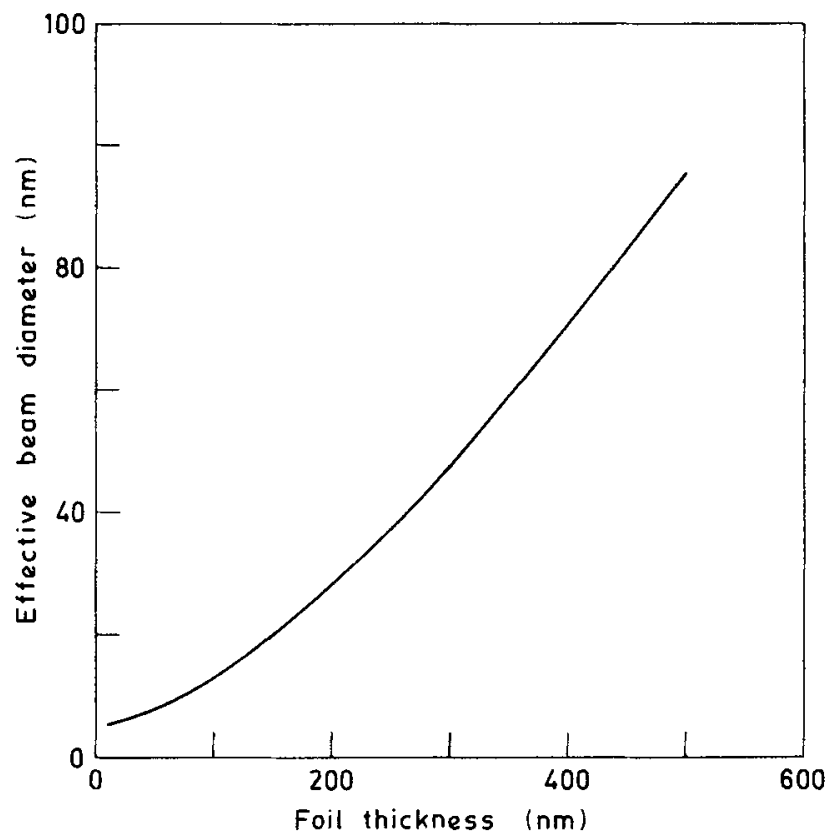

Figure 3. Variation of beam spread with foil thickness using the elastic scattering approximation.

where $P / B$ is the net peak to background intensity ratio. The total relative error in the measurement of net intensities of two characteristic peaks $\varepsilon_{A B}$ is then given by

$$
\varepsilon_{A B}=2\left[\frac{1}{I_{A}^{n}}\left\{1+\frac{2}{(P / B)_{A}}\right\}+\frac{1}{I_{B}^{n}}\left\{1+\frac{2}{(P / B)_{B}}\right\}\right]^{1 / 2} .
$$

The total relative error in the measurement of peak intensities of manganese and aluminium is plotted in figure 4 as a function of peak to background ratio, for two values of aluminium peak intensities. The relative error is large $(\sim 13 \%)$ for an aluminium count of 1000 . A counting time of $100 \mathrm{sec}$ gives rise to peak intensities of aluminium of $\sim 10000$ in the HB5 STEM; under these circumstances the error in peak intensity measurement is $\sim 4 \%$.

The sensitivity limits for chemical analysis are defined by the minimum detectable mass (MDM) and minimum mass fraction (MMF). MDM represents the sensitivity in analyzing fine particles on extraction replicas or sputtered thin films. It is inversely proportional to the $\mathrm{x}$-ray count time and electron current density. The electron current density in STEM is $10^{4} \mathrm{~A} / \mathrm{cm}^{2}$ for a $10 \mathrm{~nm}$ probe (Oppolzer and Knauer 1979). This is about 2 to 3 orders of magnitude larger than that obtained with a conventional tungsten filament. Hence the MDM is much smaller in the STEM. The minimum mass fraction is a measure of the sensitivity of detecting one element in the presence of another. It is important in analyzing precipitates or composition gradient. MMF is limited by the continuous radiation arising from the excited volume. In order to distinguish a peak from the background the peak intensity $I_{A}$ must be greater than 


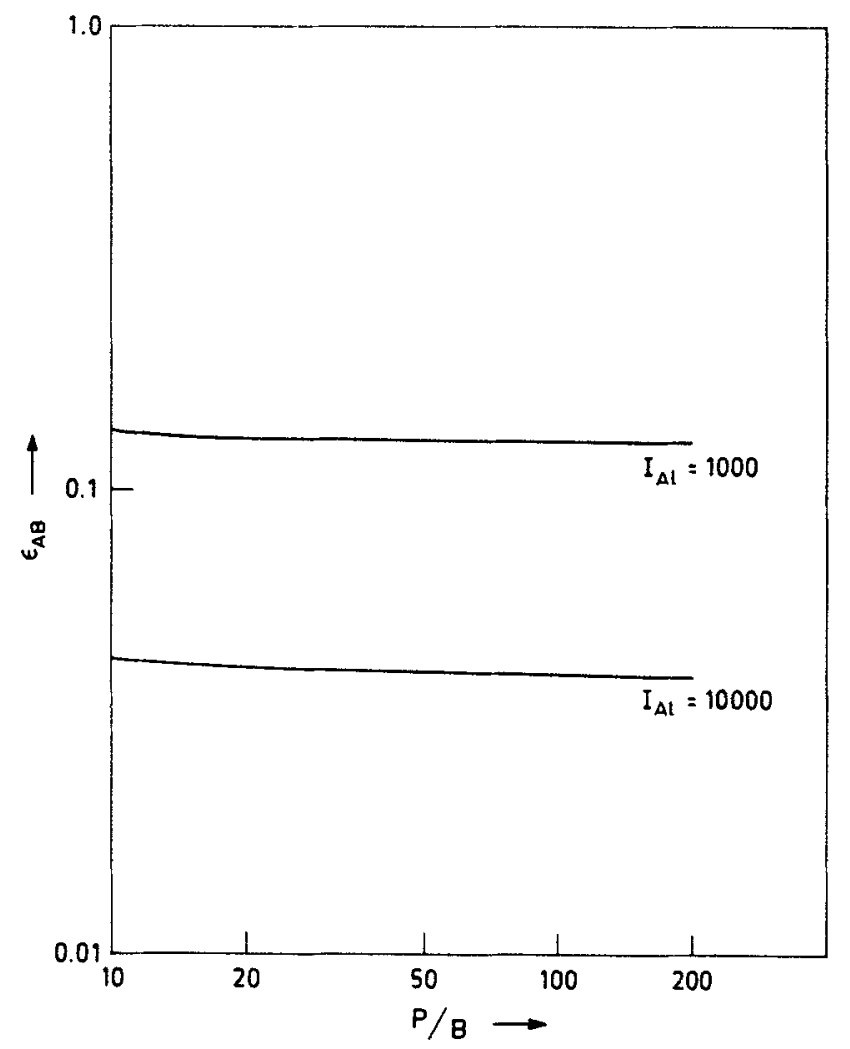

Figure 4. Dependence of the total relative error in the measurement of peak intensities on the peak to background $(P / B)$ ratio. The mean value of 0.35 is used in the calculations for $I_{\mathrm{MnK \alpha}} / I_{\mathrm{AIK} \boldsymbol{\alpha}}$.

$3\left(2 I_{A}^{b}\right)^{1 / 2}$ where $I_{A}^{b}$ is the background intensity in the energy region containing the peak of element $A$. Hence MMF can be expressed as,

$$
\left(C_{A} / C_{B}\right)_{\min }=k_{A B} \frac{3\left(2 I_{A}^{b}\right)^{1 / 2}}{I_{B}^{n}}
$$

Assuming that $I_{B}^{b} \simeq I_{A}^{b}$ (i.e. a constant background in the energy interval containing the peaks due to $A$ and $B$ ),

$$
\left(C_{A} / C_{B}\right)_{\min }=3\left(2 I_{B}^{n} \cdot P / B\right)^{-1 / 2} k_{A B}
$$

Using (12) the minimum weight fraction of manganese detectable in aluminium is plotted in figure 5 for total counts of aluminium of 5000,10000 and 50000 as a function of peak to background ratio. A value of 0.97 is used in the calculations for $k_{\mathrm{Mn}-\mathrm{Al}}$. For typical $P / B$ values of $50-100$ and total aluminium counts exceeding 10000 , the minimum detectable weight fraction of manganese in aluminium is $\sim 0.2-0.4 \%$. 


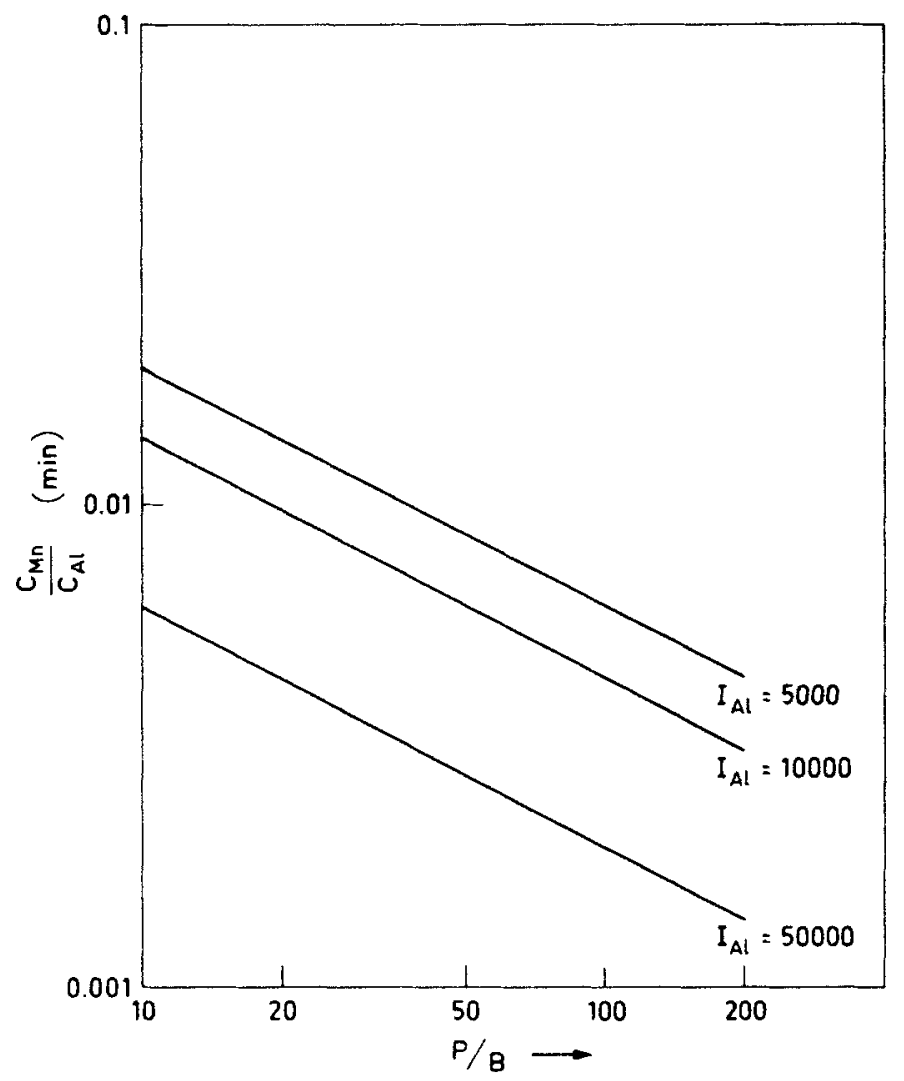

Figure 5. Variation of the minimum weight fraction of $\mathrm{Mn}$ detectable in Al with the peak to background ratio.

\section{Experimental procedure}

Cliff-Lorimer factors have been measured on a set of standard Al-Mn, Al-Fe and Al-Cu alloys supplied by the Alcan Laboratories, Kingston. Phase identification has been carried out on cold-rolled ( $\sim 90 \%$ ) and annealed (at $873 \mathrm{~K}$ ) $1100 \mathrm{Al}, 1200 \mathrm{Al}$ and 3008 aluminium alloy. The composition of these alloys and the treatments given are shown in table 1. The nature of metastable phases has been studied in $\mathrm{Al}-6 \% \mathrm{Zn}-3 \% \mathrm{Mg}$ and $\mathrm{Al}-4 \% \mathrm{Cu}$ alloys. Details of thermal treatments to which these alloys were subjected are also shown in table 1 . The samples were chemically thinned in a mixture of orthophosphoric acid, sulphuric acid and nitric acid followed by electropolishing in a Struers Tenupol unit using methanol $(90 \%$ by voi) and perchloric acid (10\% by vol). They were heated for $300 \mathrm{sec}$ at $373 \mathrm{~K}$ in the prevacuum of the sTEM prior to examination. X-ray spectra were obtained from the phases using a typical count time of $100 \mathrm{sec}$.

The results of $\mathrm{x}$-ray microanalysis can be complicated by surface films on thin foils or the appearance of 'systems peaks'. Surface films lead to abnormal intensity ratio near the edge of the foil. This effect has been observed in a number of aluminium-base alloys. 
Table 1. Composition and thermal treatment of aluminium alloys.

\begin{tabular}{|c|c|c|}
\hline System & Composition & Treatment \\
\hline $1100 \mathrm{Al}$ & $\begin{array}{l}\text { Fe } 0.55 \% \\
\text { Si } 0.15 \% \\
\text { Al } 99.0 \% \mathrm{~min}\end{array}$ & $\begin{array}{l}\text { Hunter cast } \\
\text { - Cold rolled } 90 \% \\
\text { annealed at } 873 \mathrm{~K} \text { for } 1 \mathrm{~h}\end{array}$ \\
\hline $1200 \mathrm{Al}$ & $\begin{array}{l}\text {-do- }+ \text { small amount of } \\
\text { chromium }\end{array}$ & -do- \\
\hline 3008 alloy & $\begin{array}{l}\text { Mn } 1.38 \% \text {, Fe } 0.46 \% \\
\text { Si } 0.12 \%, \mathrm{Zr} 0.29 \% \\
\text { Cu } 0.09 \% \text {, Ti } 0.016 \% \\
\text { balance Al. }\end{array}$ & -do- \\
\hline $\mathrm{Al}-\mathrm{Zn}-\mathrm{Mg}$ & $\mathrm{Al}-6 \% \mathrm{Zn}-3 \% \mathrm{Mg}$ & $\begin{array}{l}\text { Solution treated at } 748 \mathrm{~K} 1 \mathrm{hr} \text { quenched } \\
\text { to } 473 \mathrm{~K} \text { for } 1 \mathrm{~min} \text {. and then maintained } \\
\text { at } 294 \mathrm{~K} \text { for } 1 \mathrm{~min} \text {., aged at } 448 \mathrm{~K}\end{array}$ \\
\hline $\mathrm{Al}-\mathrm{Cu}$ & $\mathrm{Al}-4 \% \mathrm{Cu}$ & $\begin{array}{l}\text { Solution treated at } 798 \mathrm{~K} \text { for } 24 \mathrm{hr} \text { in } \\
\text { vaccum, quenched in water and aged at } \\
513 \mathrm{~K} \text { for } 4 \mathrm{~h} \text {. }\end{array}$ \\
\hline
\end{tabular}

Careful examination of the standard samples and commercial aluminium alloys reveal no significant difference in intensity ratio at the foil edge. The origin of 'systems peaks' and the methods of minimizing them are discussed in detail by Zaluzec (1979), $\mathrm{X}$-ray counts from holes present in the particles show that the total hole count is less than $1 \%$ of that measured in the thinnest region of the particle-consequently complications due to system peaks can be ignored.

\section{Results}

\subsection{Determination of $K$ values}

The microstructure of the standard $\mathrm{Al}-\mathrm{Mn}$ and $\mathrm{Al}-\mathrm{Cu}$ alloys and the x-ray spectra from the particles are presented in figures 6 and 7. The Al-Mn alloy reveals irregularlyshaped particles while those in $\mathrm{Al}-\mathrm{Cu}$ are in the form of discs or are irregularly shaped. The intensity ratio, $I_{\mathrm{MnK} \alpha} / I_{\mathrm{AIK} \alpha}$ is constant in the various regions of the particle and also for a large number of particles. The mean value of the intensity ratio is $0.35 \pm 0.01$. Selected area diffraction patterns obtained in the TEM and STEM reveal that these particles are $\mathrm{Al}_{6} \mathrm{Mn}$. These two results are used to obtain a $k$ value (the Cliff-Lorimer factor) of $0.97 \pm 0.03$. The results obtained from the $\mathrm{Al}-\mathrm{Cu}$ and $\mathrm{Al}-\mathrm{Fe}$ alloys show considerable scatter possibly because of the fact that the particles do not occupy the entire thickness of the foil. Analysis of selected area diffraction patterns indicates that the particles are $\mathrm{CuAl}_{2}$ and $\mathrm{FeAl}_{3}$. The $k$ values obtained in this study are presented in table 2 along with other available data based on theoretical calculations and experimental measurements. The results are in good agreement with the theoretical calculations by Goldstein et al (1977) and Zaluzec (1979) and experimental measurements of Cliff and Lorimer (1975) and Woods et al (1981). 


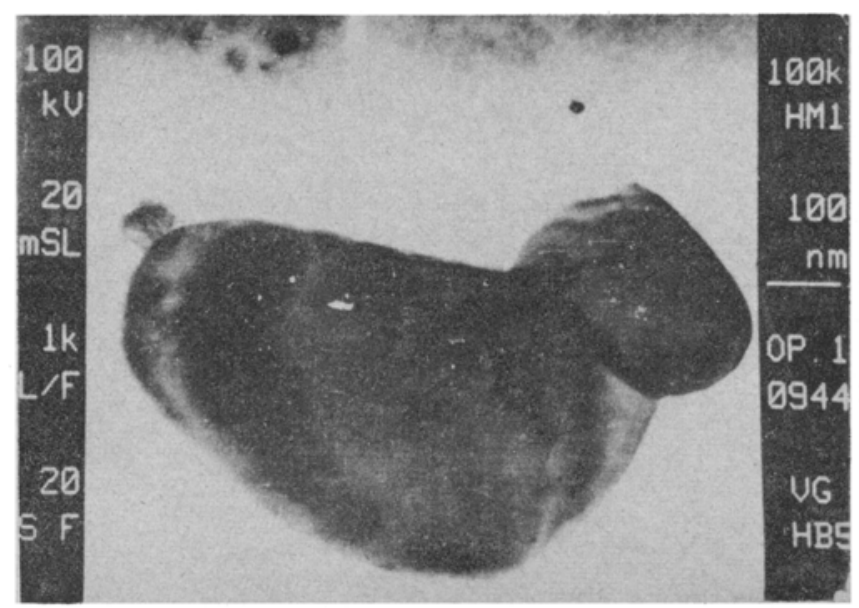

(a)

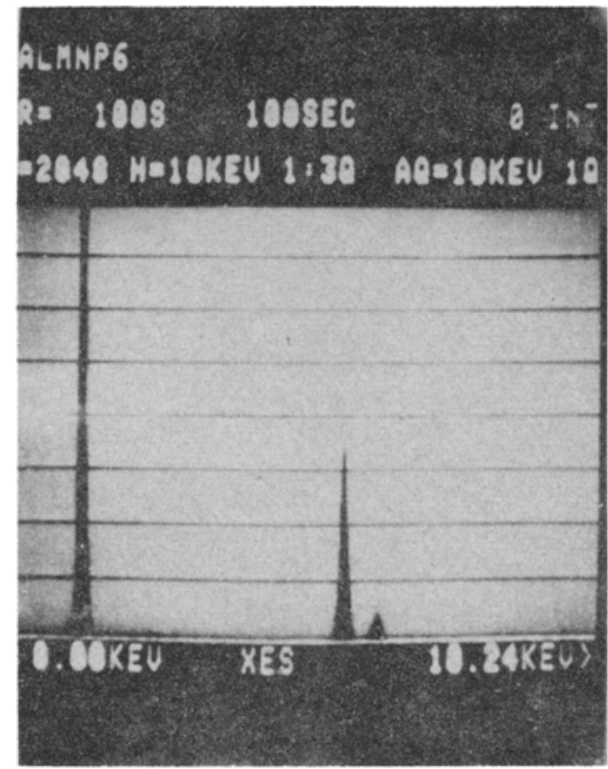

(b)

Figure 6. a. Typical STEM micrograph of $\mathrm{Al}_{6} \mathrm{Mn}$ particle in the standard $\mathrm{Al}-\mathrm{Mn}$ alloy. b. X-ray spectrum from the particle showing AlK, $\mathrm{MnK} \alpha$ and $\operatorname{MnK} \beta$ peaks.

\subsection{Phase identification}

Commercially pure aluminium contains the following binary and ternary phases (Porter and Westengen 1981); $\mathrm{Al}_{3} \mathrm{Fe}$ (monoclinic), $\mathrm{Al}_{6} \mathrm{Fe}$ (C-centred orthorhombic), $\mathrm{Al}_{m} \mathrm{Fe}$ (body-centred tetragonal), $\mathrm{Al}_{2} \mathrm{Fe}$ (unknown structure characterized by highly irregular diffraction patterns), $\alpha$-AlFeSi (b.c.c.), $\alpha^{\prime}$ AlFeSi (hexagonal), $\alpha^{\prime \prime}$ AlFeSi (tetragonal) and $\beta^{\prime}$ AIFeSi (monoclinic).

$\mathrm{X}$-ray spectra from one of the particles and the matrix in 1200 aluminium are shown in figure 8. The particle shows prominant peaks due to $\mathrm{Al}, \mathrm{Si}, \mathrm{Cr}$ and $\mathrm{Fe}$. Several particles show only $\mathrm{Al}, \mathrm{Cr}$ and $\mathrm{Fe}$ peaks. The intensity ratios, viz $I_{\mathrm{SiK} \alpha} / I_{\mathrm{AIK} \alpha}, I_{\mathrm{CrK} \alpha} / I_{\mathrm{AlK} \alpha}$ and 

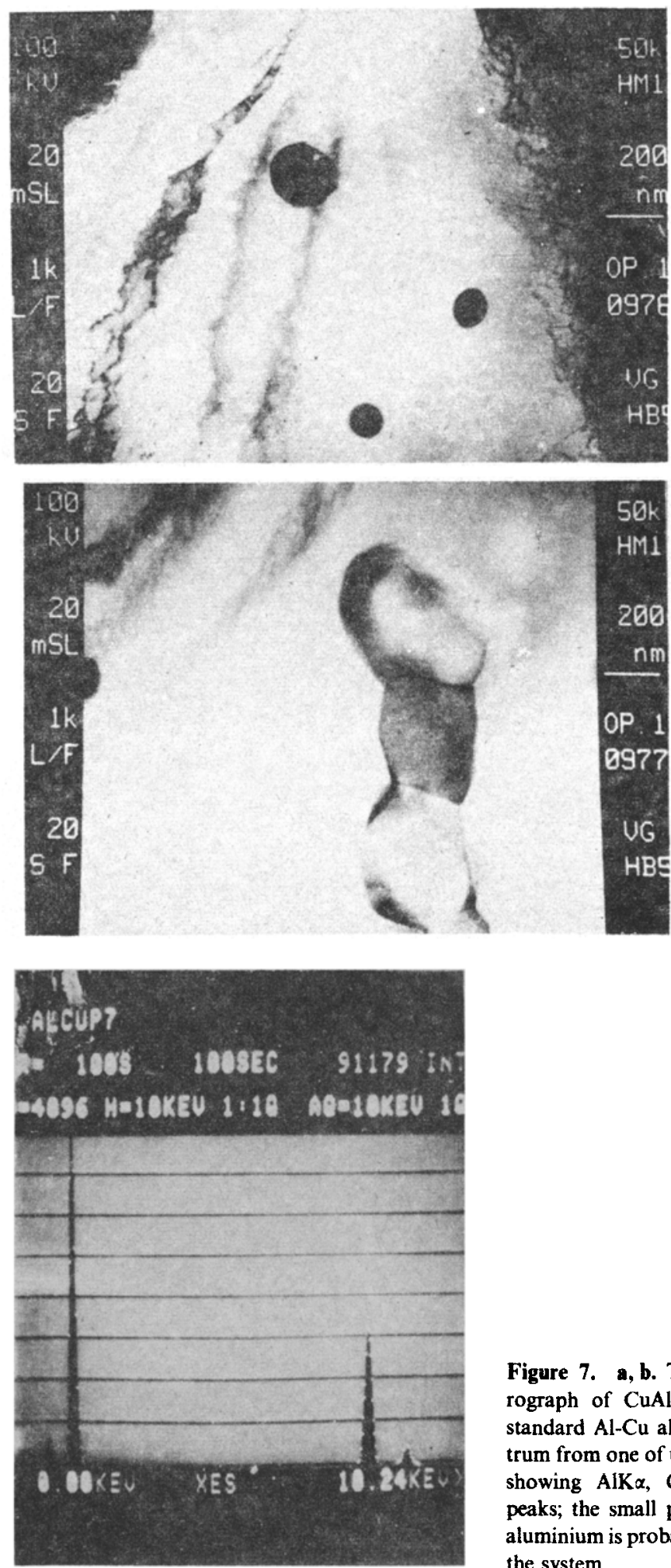

Figure 7. a, b. Typical STEM micrograph of $\mathrm{CuAl}_{2}$ particles in the standard $\mathrm{Al}-\mathrm{Cu}$ alloy. c. X-ray spectrum from one of the $\mathrm{CuAl}_{2}$ particles showing $\operatorname{AIK} \alpha, \operatorname{CuK} \alpha$ and $\operatorname{CuK} \beta$ peaks; the small peak to the left of aluminium is probably due to noise in the system. 
Table 2. Cliff-Lorimer $(k)$ factor for $\mathrm{Mn}, \mathrm{Fe}$ and $\mathrm{Cu}$ with respect to $\mathrm{Al}$.

\begin{tabular}{|c|c|c|c|c|c|c|}
\hline \multirow[b]{2}{*}{ System } & \multirow[b]{2}{*}{$\begin{array}{l}\text { Present } \\
\text { work }\end{array}$} & \multicolumn{5}{|c|}{$k$ values } \\
\hline & & $\begin{array}{l}\text { Goldstein } \\
\text { et al (1977) }\end{array}$ & $\begin{array}{c}\text { Zaluzec } \\
(1979)\end{array}$ & $\begin{array}{l}\text { Schreiber and } \\
\text { Wims (1981) }\end{array}$ & $\begin{array}{c}\text { Cliff and } \\
\text { Lorimer (1975) }\end{array}$ & $\begin{array}{l}\text { Woods } \\
\text { et al (1981) }\end{array}$ \\
\hline $\mathrm{Mn}-\mathrm{Al}$ & $0.97 \pm 0.03$ & $1 \cdot 17$ & 1.23 & 0.67 & 0.86 & 1.20 \\
\hline Fe-Al & $1 \cdot 15 \pm 0.1$ & $1 \cdot 19$ & 1.28 & 0.78 & 0.89 & $1 \cdot 16$ \\
\hline $\mathrm{Cu}-\mathrm{Al}$ & $1.60 \pm 0.15$ & 1.42 & 1.60 & 0.96 & $1 \cdot 11$ & $1 \cdot 42$ \\
\hline
\end{tabular}

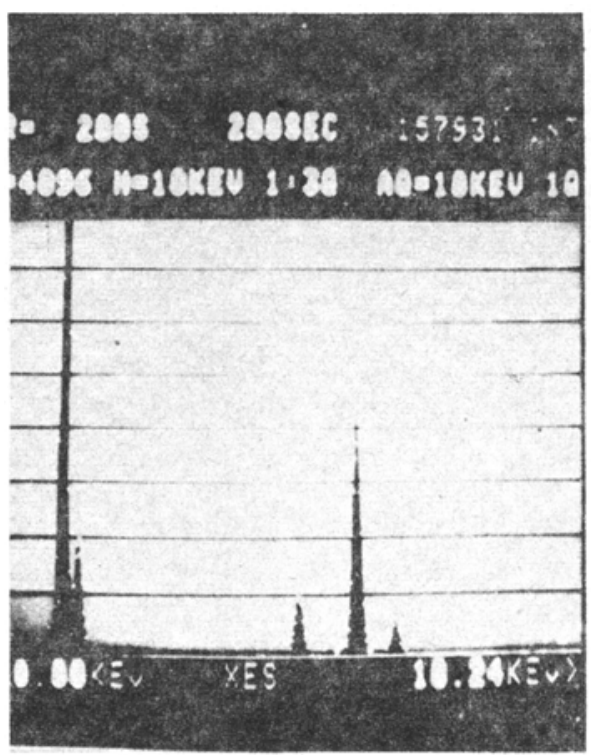

(a)

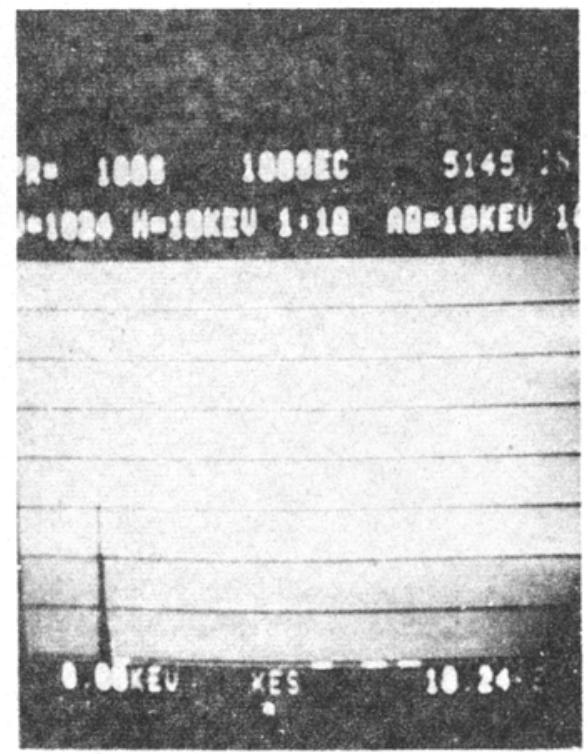

(b)

Figure 8. X-ray spectra from a. a particle in 1200 aluminium showing AlK, SiK, CrK $\alpha$, FeK $\alpha$ and $\mathrm{FeK} \beta$ peaks and $b$. the matrix showing only the AlK peak.

$I_{\mathrm{FeK} \alpha} / I_{\mathrm{AIK} \alpha}$ show considerable scatter possibly due to improper orientation of the foil with respect to the electron beam and due to the fact that the particles do not occupy the entire depth of the foil. This problem has been overcome by carrying out $x$-ray microanalysis on the particles sticking to the edge of the foil (figure 9). Analysis from these particles should minimize contribution from the aluminium matrix. The results of analysis from 4 different regions of the particle in figure 9 are summarized in table 3 . The $\mathrm{SiK} \alpha$ to $\mathrm{AlK} \alpha$ and $\mathrm{CrK} \alpha+\mathrm{FeK} \alpha$ to $\mathrm{AlK} \alpha$ intensity ratio are about the same; it is to be noted that $\mathrm{CrK} \alpha+\mathrm{FeK} \alpha$ to $\mathrm{SiK}$ ratio is also nearly the same. Another method of overcoming this problem is to extract the particles using a mixture of 8-hydroxy quinoline, methanol, chloroform and benzoic acid (Cogan et al 1978; Hodgson and Parker 1981). This method is currently being tried for the extraction of particles. Two typical $\mathrm{x}$-ray spectra from particles in 1100 aluminium are shown in figures $10 \mathrm{a}, \mathrm{b}$ 


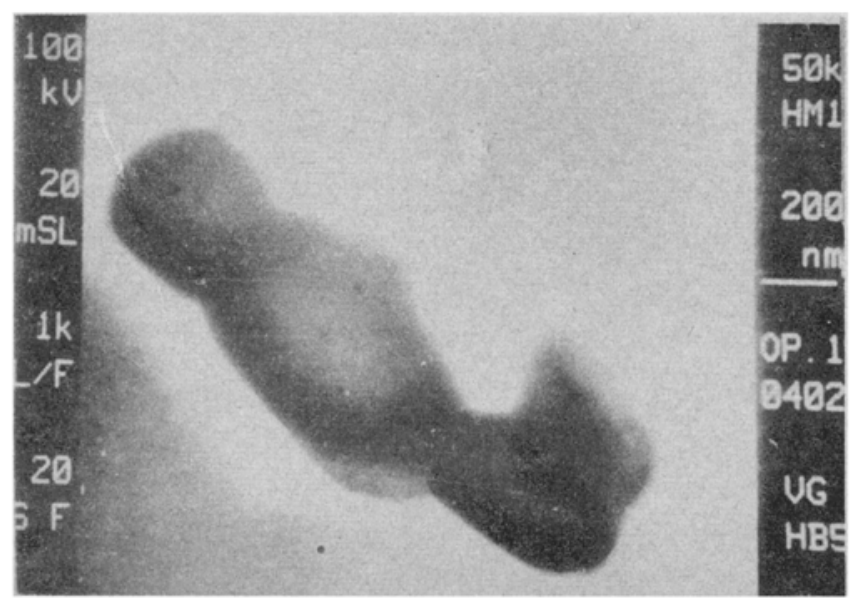

Figure 9. Typical STEM micrograph of a particle in 1200 aluminium sticking to the edge of the foil.

Table 3. Intensity ratio from various regions of the particle shown in figure 9.

\begin{tabular}{cccc}
\hline & \multicolumn{3}{c}{ Ratio } \\
\cline { 2 - 4 } Region & $I_{\text {SiK } \alpha} / I_{\text {AIK } \alpha}$ & $I_{\text {CrK } \alpha} / I_{\text {AIK } \alpha}$ & $I_{\text {FeK } \alpha} / I_{\text {AIK } \alpha}$ \\
\hline 1 & 0.13 & 0.05 & 0.43 \\
2 & 0.12 & 0.05 & 0.44 \\
3 & 0.14 & 0.07 & 0.43 \\
4 & 0.16 & 0.10 & 0.46 \\
\hline
\end{tabular}

revealing prominent peaks due to $\mathrm{Al}, \mathrm{Fe}, \mathrm{Mn}$ and $\mathrm{Cu}$; convergent beam diffraction pattern obtained from the second particle is shown in figure $10 \mathrm{c}$, the pattern corresponds to cubic AlFeSi. The intensity ratio obtained for particles showing $\mathrm{Al}$ and $\mathrm{Fe}$ peaks matches well with that obtained for $\mathrm{Al}_{3} \mathrm{Fe}$ in the standard Al-Fe alloy. A few $\mathrm{CuAl}_{2}$ particles have also been identified.

Typical microstructures of the constituents in the 3008 alloy are shown in figure $11 \mathrm{a}, \mathrm{b}$ and the diffraction pattern from one of these particles in figure $11 \mathrm{c}$. The pattern corresponds to $\mathrm{Al}_{6} \mathrm{Mn}$. It was not possible to identify any coarse zirconiumrich particles by diffraction. Typical $x$-ray spectra from the particles are shown in figure 11d, e with prominent $\mathrm{Al}$ and $\mathrm{Mn}$ or $\mathrm{Al}, \mathrm{Mn}$ and $\mathrm{Fe}$ peaks. The ratio of $\mathrm{Fe}+\mathrm{Mn}$ to $\mathrm{Al}$ intensity is constant within the limits of experimental error for a large number of particles irrespective of their morphology. The $x$-ray spectrum from the matrix shows only an aluminium peak (figure 11f). Careful examination of the sample reveals very fine zirconium-rich particles; a typical micrograph is shown in figure 12a and the $x$-ray spectrum in figure $12 \mathrm{~b}$ revealing prominent $\mathrm{AlK} \alpha$ and $\mathrm{ZrL} \alpha$ peaks. The intensity ratio of zirconium to aluminium is 0.22 . 

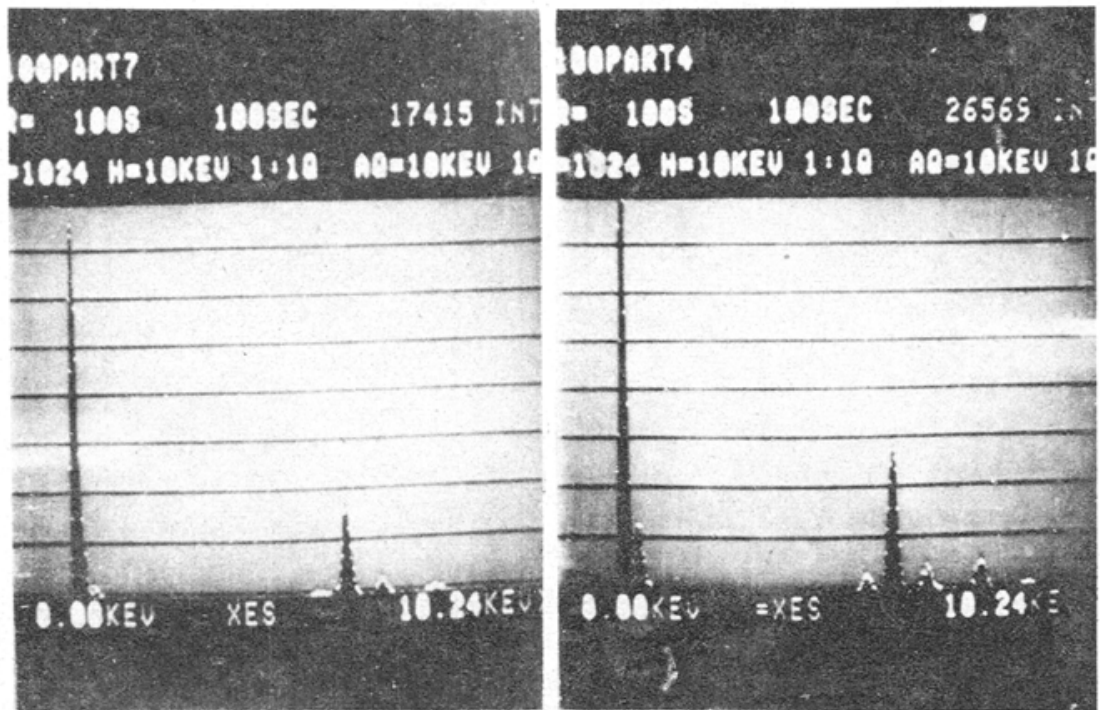

(a)

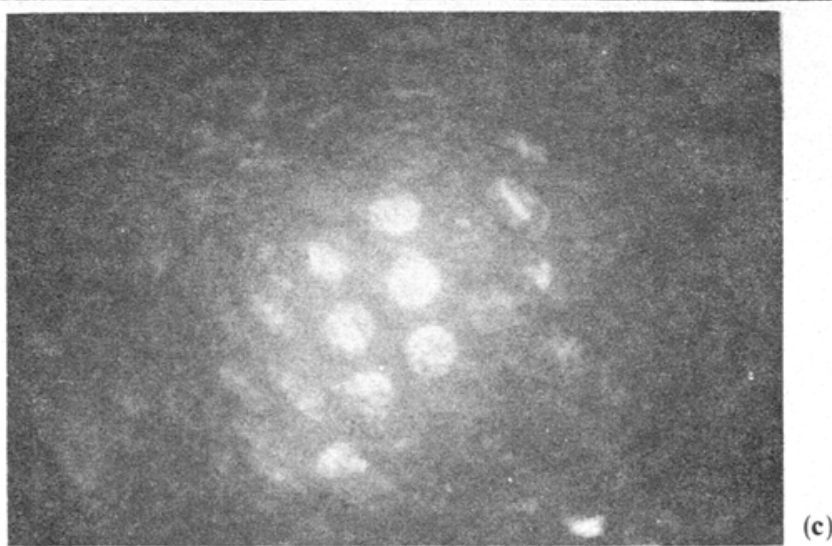

(b)

Figure 10. X-ray spectra from particles in 1100 aluminium showing a. AlK $\alpha, \mathrm{FeK} \alpha$ and FeK $\beta$ peaks and b. AlK $\alpha, \operatorname{SiK} \alpha, \operatorname{MnK} \alpha, \operatorname{FeK} \alpha, \operatorname{FeK} \beta, \operatorname{CuK} \alpha$ and $\operatorname{CuK} \beta$ peaks, c. Convergent beam diffraction pattern from the particle in (b).

\subsection{Formation of metastable phases}

The transition phases formed in the $\mathrm{Al}-\mathrm{Zn}-\mathrm{Mg}$ and $\mathrm{Al}-\mathrm{Cu}$ alloys were investigated by $\mathrm{x}$-ray analysis and microdiffraction. Figure 13 is a bright field micrograph of metastable phases in $\mathrm{Al}-\mathrm{Zn}-\mathrm{Mg}$ formed by step quenching. The needles form along the $\langle 100\rangle$ directions of $\mathrm{Al}$. The selected area diffraction pattern from the area is shown in figure 13 (a) while figure $13 \mathrm{~b}, \mathrm{c}, \mathrm{d}$ represent microdiffraction patterns from the precipitate at approximate illumination half angles $(\alpha)$ of 8,4 and $1.7 \mathrm{mrad}$ respectively. The compositional difference between the metastable and equilibrium precipitates is clearly brought out in figure 14 . The micrograph shows both needle-like metastable precipitates (marked as 2) and equilibrium precipitates (marked as 1 ) $\eta-\mathrm{MgZn}_{2}$. The $\mathrm{X}$ ray spectrum from the equilibrium precipitates shows $\mathrm{ZnL} \alpha$ and $A \mathrm{KK} \alpha$ peaks. The difference in the relative enrichment of the peaks is evident. 


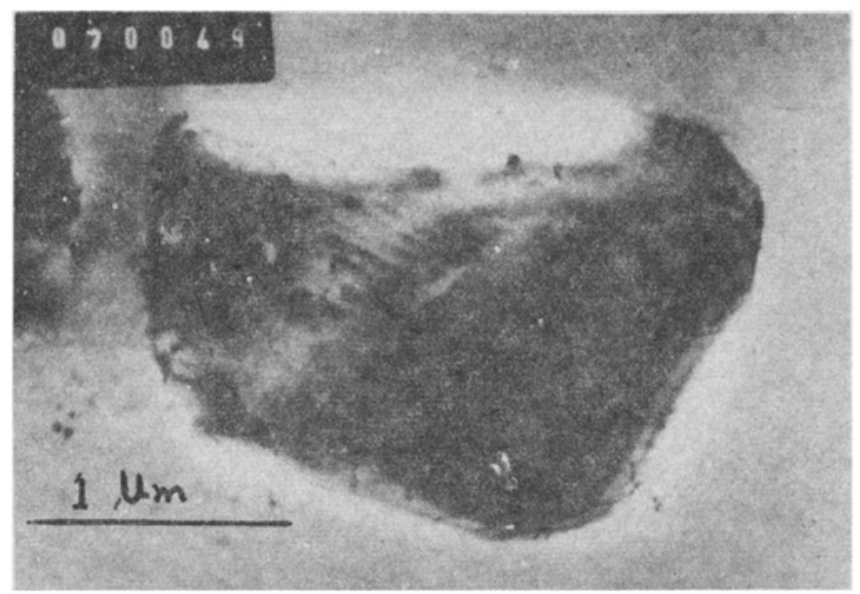

(a)

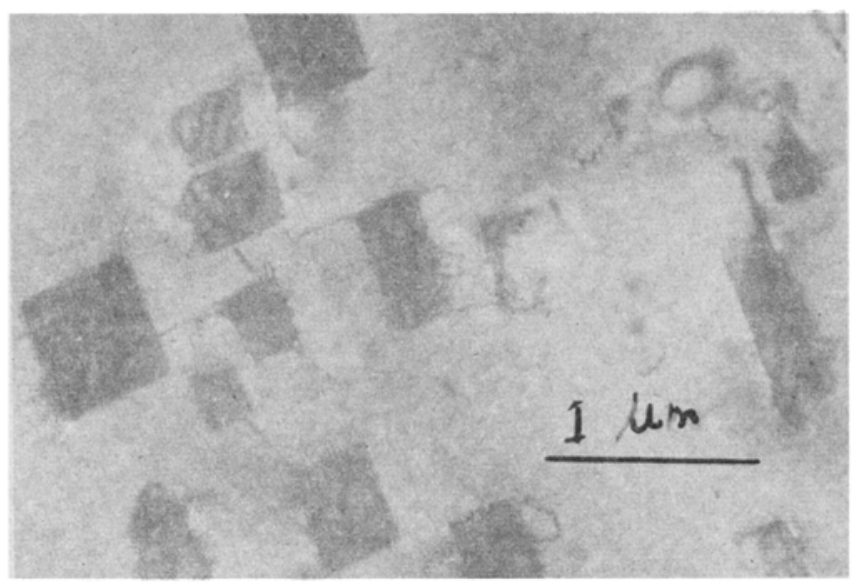

(b)

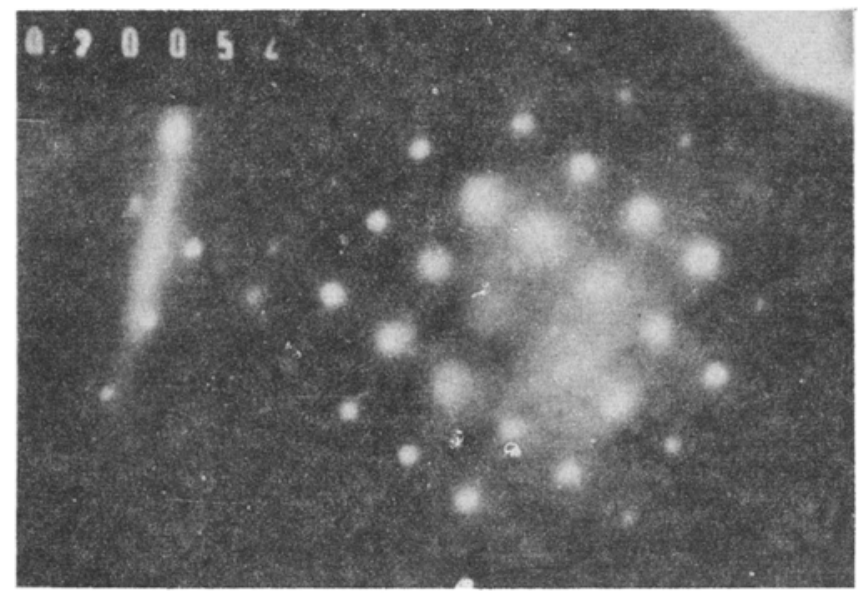

(c) 


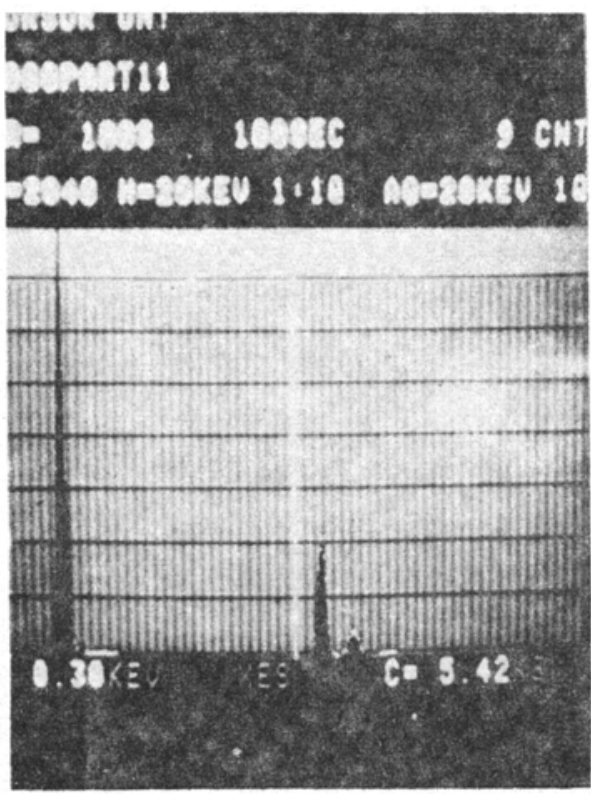

(d)

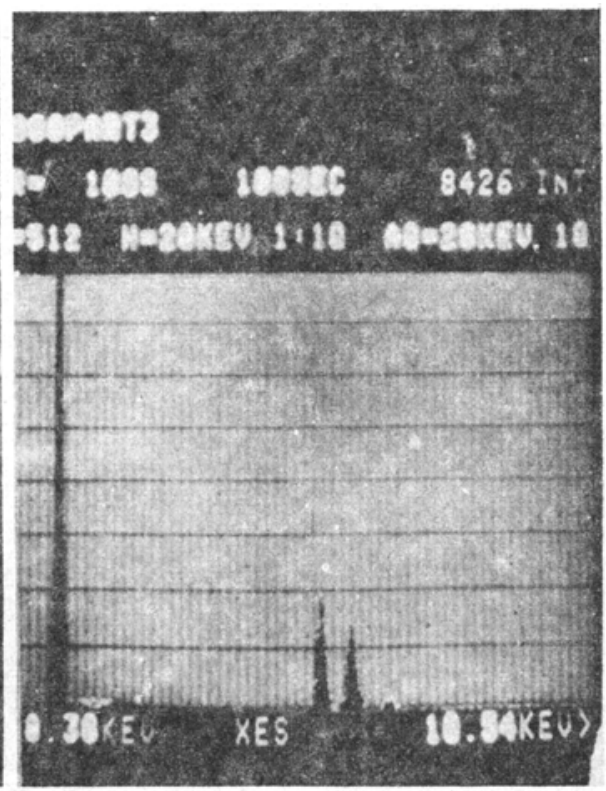

(e)

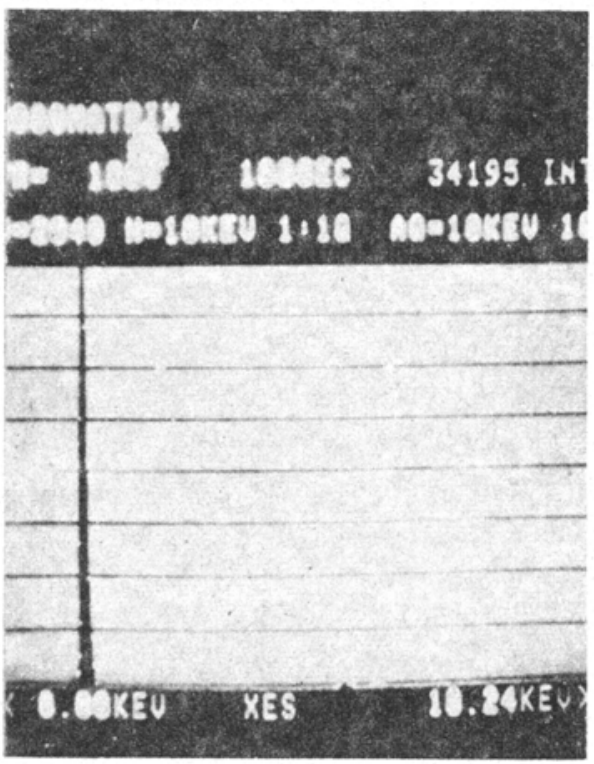

(f)

Figure 11. a, b. Microstructures of particles in the 3008 alloy. c. SAD pattern from one of the particles, $\mathrm{Al}_{6} \mathrm{Mn}$ beam direction [112]. d, e. X-ray spectra from the particles showing $\mathrm{AlK} \alpha, \mathrm{MnK} \alpha$ and $\mathrm{K} \beta$ and $\mathrm{FeK} \alpha$ and $\mathrm{K} \beta$ peaks. f. $\mathrm{X}$-ray spectrum from the matrix showing only the AlK $\alpha$ peaks. 

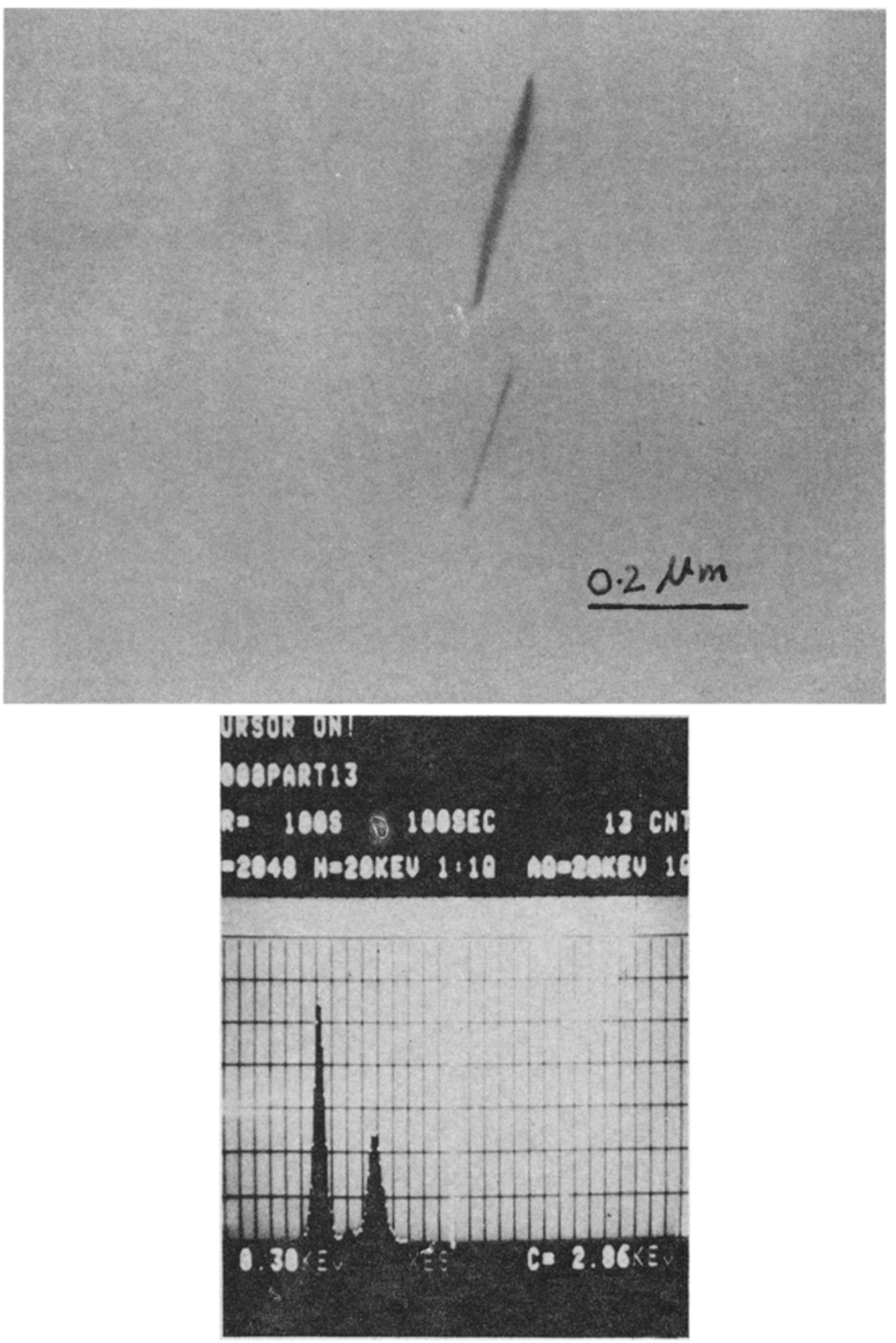

Figure 12. a. STEM micrograph of zirconium-rich particles in the 3008 alloy b. X-ray spectrum from one of the particles in (a) showing $A l K \alpha$ and $\operatorname{ZrL} \alpha$ peaks. 


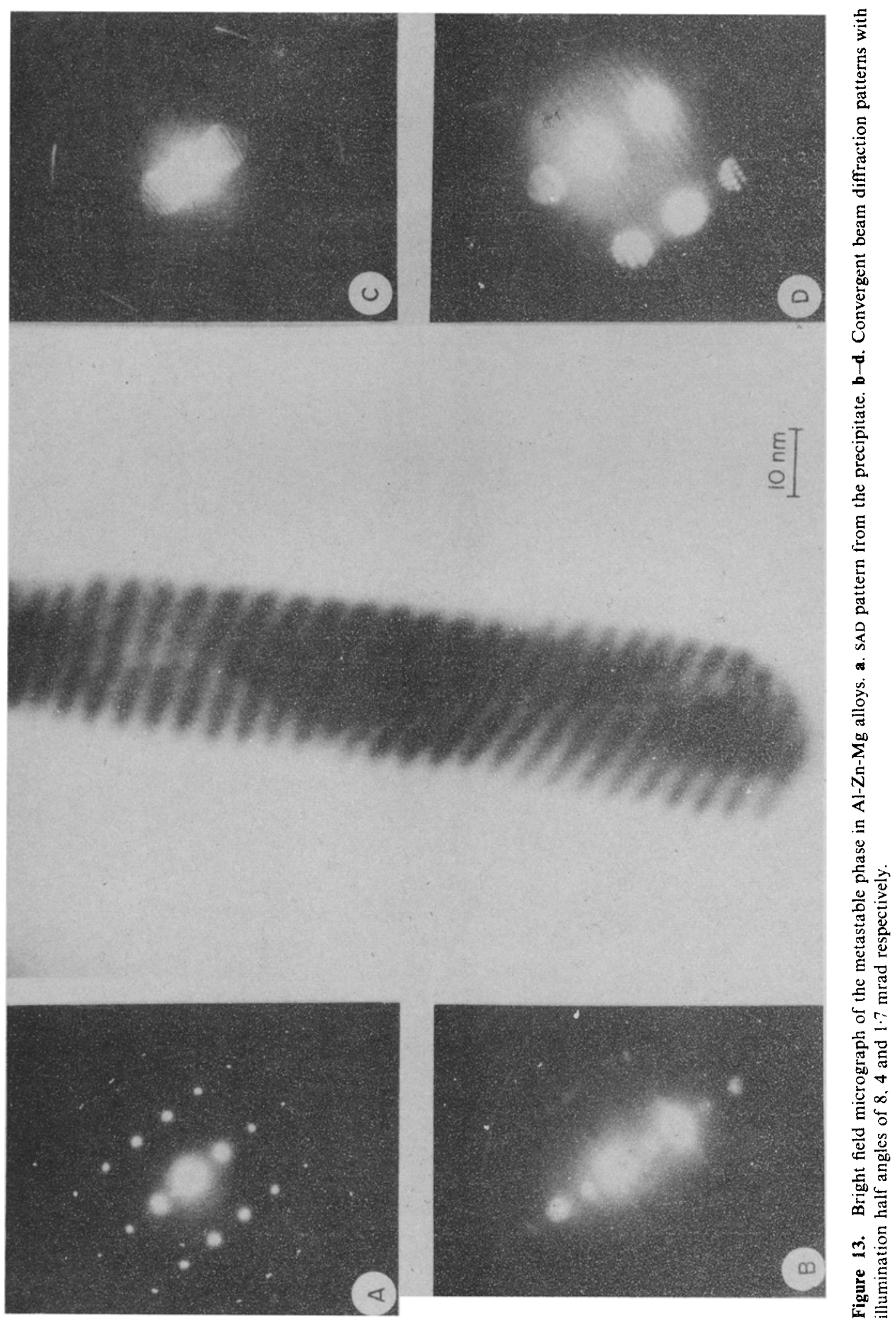



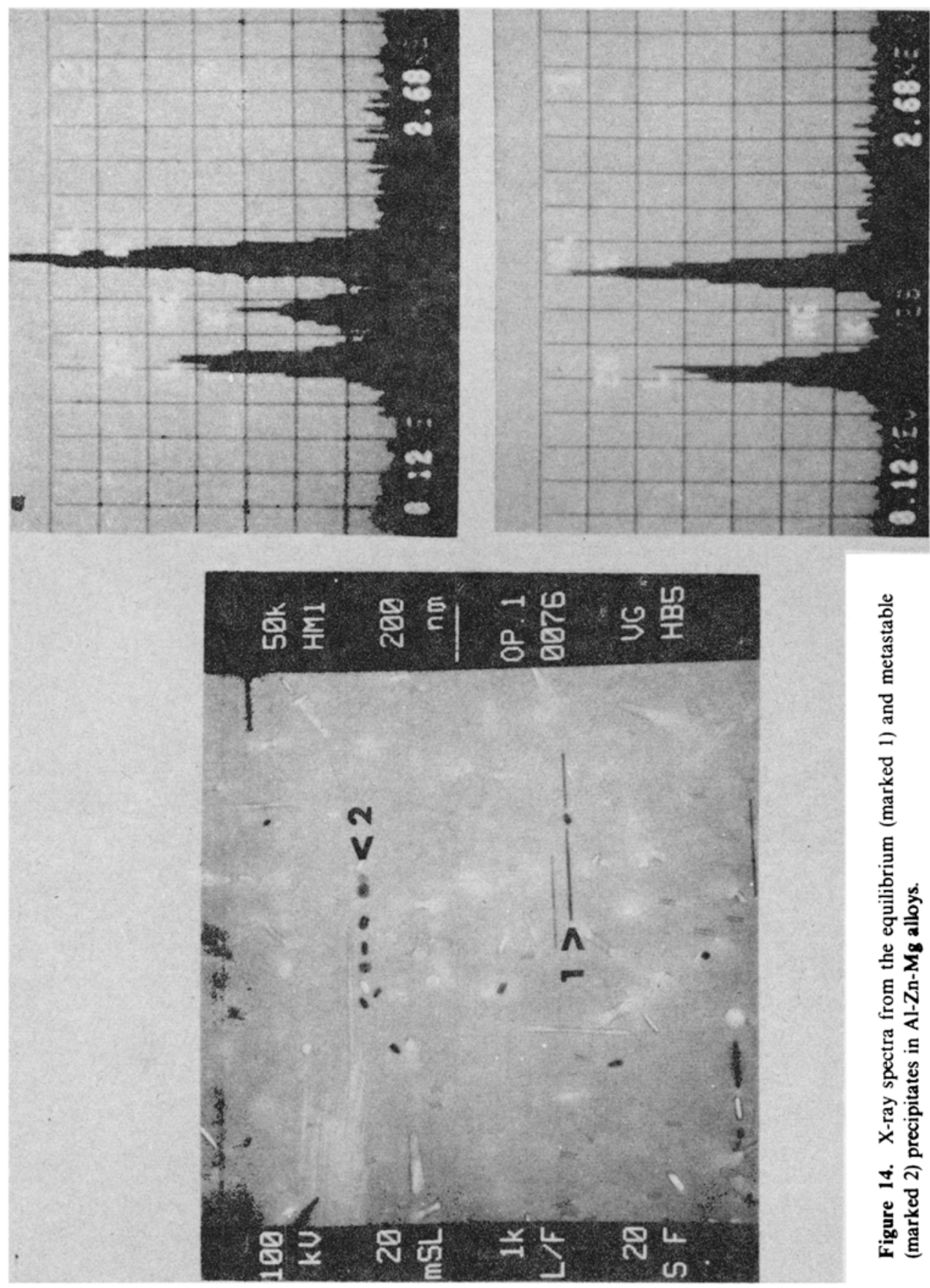

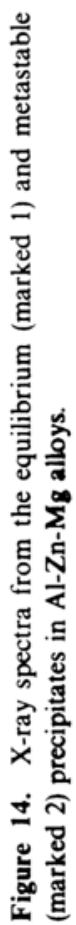




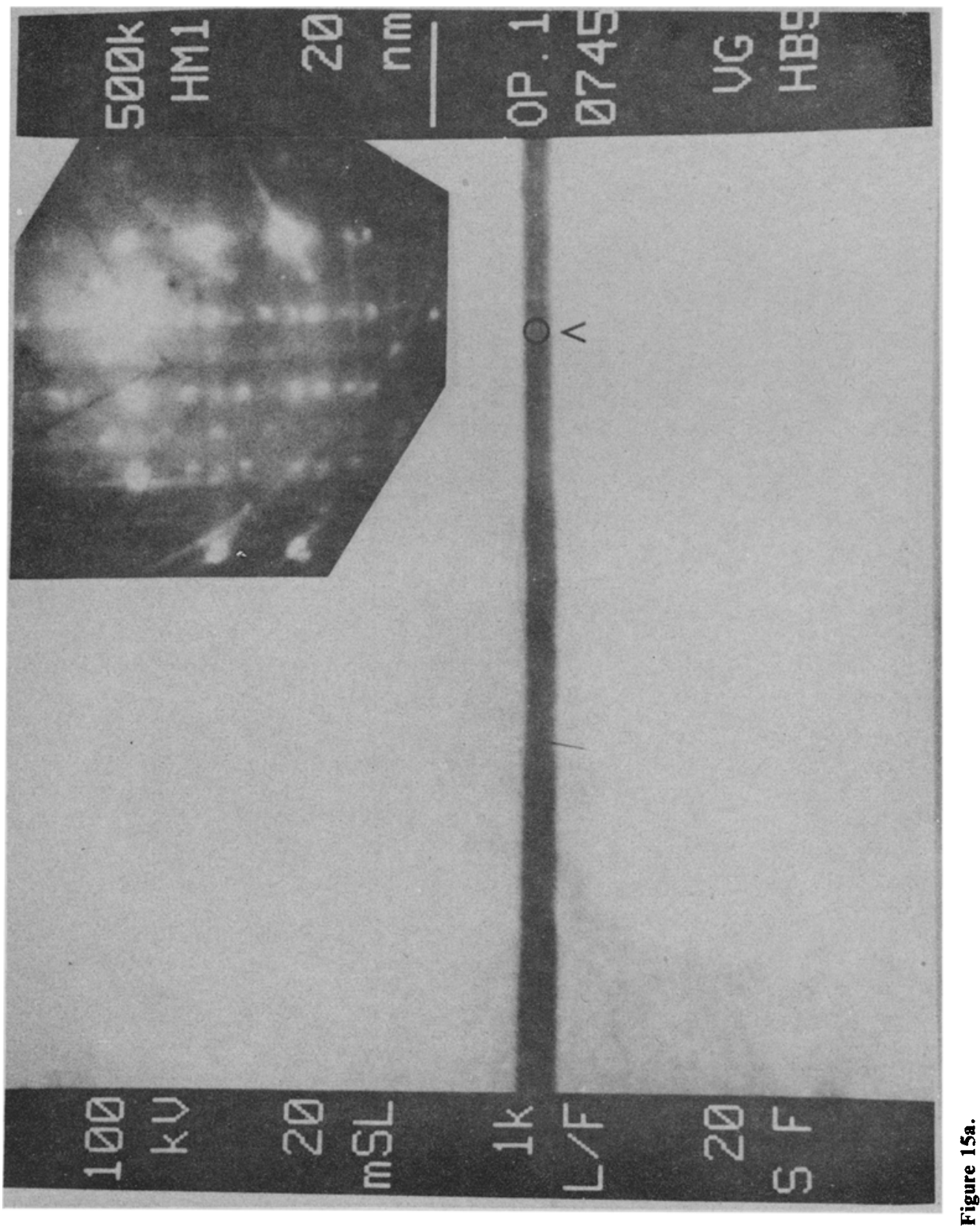




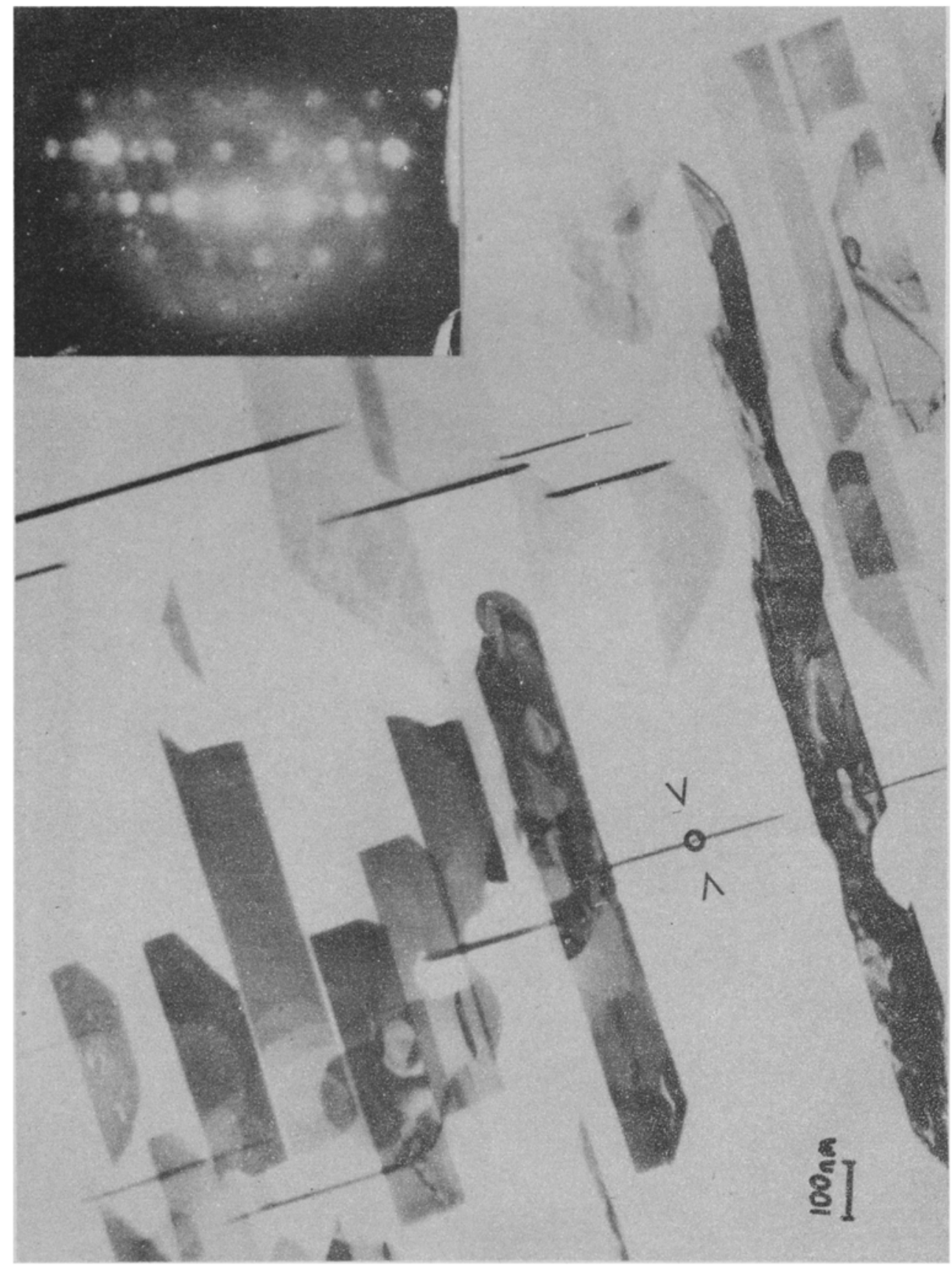

芒 


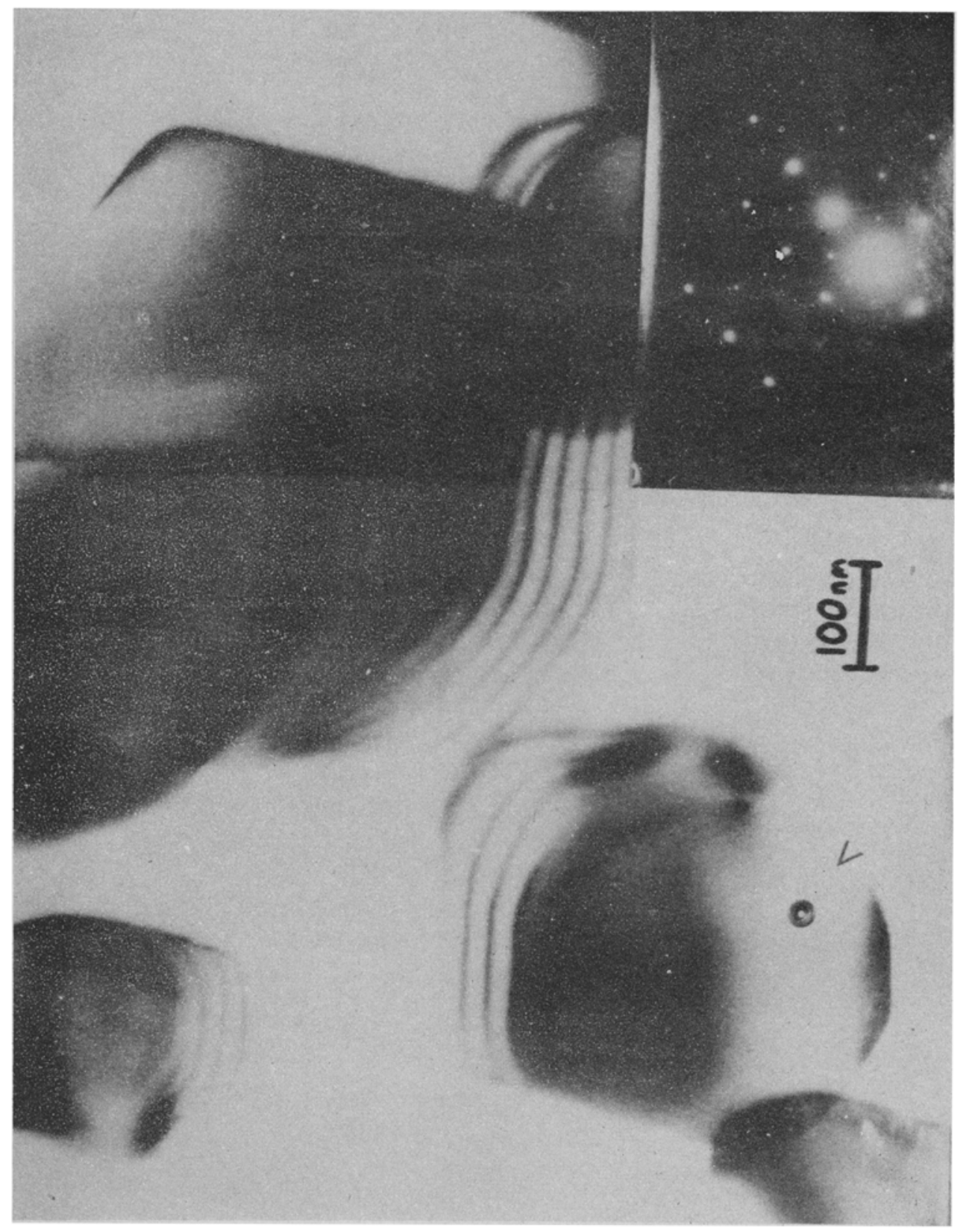

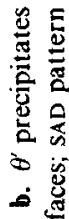

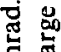

$\div$

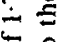

$\div 9$

욜

임

용

둥

莯

冚

듬

के

ن

曾

5

잉

는

ह

옹

E

的

跣

등 홍

풀

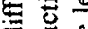

范

해음

둥

है

응 앵

की

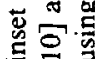

政

$\because \asymp$

总藏

32 일

立范号

$\Xi$,

号

过

퐁.

के $E$

-

ง

망

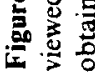


$\theta^{\prime}$ platelets in $\mathrm{Al}-4 \% \mathrm{Cu}$ alloys are shown in figure 15 . The matrix has a cube orientation with a single $\theta^{\prime}$ precipitate viewed edge on. The inset microdiffraction pattern has been obtained from the region indicated using $\alpha$ of $1.7 \mathrm{mrad}$. An array of $\theta^{\prime}$ precipitates viewed $\theta^{\prime}$ with beam direction close to matrix $[110]_{a}$ is shown in figure $15 \mathrm{~b}$. The microdiffraction pattern obtained from an approximately $3 \mathrm{~nm}$ area centred on $\mathrm{a} \theta^{\prime}$ platelet at the portion indicated using $\alpha$ of $1.7 \mathrm{mrad}$ is shown in the figure $15 \mathrm{~b}$. Figure $15 \mathrm{c}$ shows a stack of $\theta^{\prime}$ platelets viewed normal to their large faces. The SAD pattern was taken at the position shown from an isolated $\theta^{\prime}$ platelet using zero objective lens excitation. The beam diameter in the plane of the specimen in this mode is $\sim 10 \mathrm{~nm}$. The $\theta^{\prime}$ reflections are seen near the forbidden (110) matrix reflections.

\section{Conclusions}

(i) The principles of $x$-ray microanalysis using the dedicated STEM are presented in this paper with particular emphasis on absorption correction to be applied when examining particles, beam broadening in foils of aluminium, precision of intensity measurements and detection limits; (ii) Hole count measurements indicate that the systems background effect can be ignored while examining the specimens in the VG HB5 STEM. (iii) The Cliff-Lorimer factor for converting the observed intensity ratio into weight fraction ratio has been measured for $\mathrm{Mn}, \mathrm{Fe}$ and $\mathrm{Cu}$ with $\mathrm{Al}$ as the base as $0.97 \pm 0.03$, $1 \cdot 15 \pm 0.1$ and $1.60 \pm 0.15$ respectively. These values are in good agreement with other experimental measurements and theoretical calculations. (iv) The peak intensity ratio obtained from a number of particles show a wide scatter possibly due to the contribution from the aluminium matrix. However, consistent results are obtained when particles at the edge of the foil are considered. The results also focus on the necessity of carrying out $x$-ray microanalysis on extracted particles. (v) The following phases have been identified in 1100 and $1200 \mathrm{Al}$ and 3008 alloys: $\mathrm{Al}_{3} \mathrm{Fe}$, cubic $\mathrm{AlFeSi}$, $\mathrm{CuAl}_{2}, \mathrm{Al}_{6} \mathrm{Mn}$ and possibly $\mathrm{ZrAl}_{3}$. (vi) Microdiffraction and $\mathrm{x}$-ray microanalysis have been used to study the structure and composition of metastable phases in Al-Cu and $\mathrm{Al}-\mathrm{Zn}-\mathrm{Mg}$ alloys.

\section{Acknowledgements}

The authors are grateful to Dr D Lloyd of Alcan, Kingston, Canada, for valuable discussion and to NSERC (Canada) for research support.

\section{References}

Cliff G and Lorimer G W 1975 J. Microsc. 103203

Cogan S F, Gayle F W, Klein J D, Cocks F H and Shepard M L 1978 J. Mater. Sci. 132687

Cowley J M 1982 National Seminar on high resolution and analytical microscopy (Kalpakkam)

Goldstein J I, Costley J L, Lorimer G W and Read S J B 1977 (ed) O Johari (Chicago: IITRI) p. 315

Heinrich K F J 1966 The electron microprobe (eds) T D McKinley, K F J Heinrich and D B Wittry (New York: Wiley) p. 296

Hodgson P and Parker B A 1981 J. Mater. Sci. 161343

Jones I P and Loretto M H 1981 J. Microse. 1243

Joy D C 1981 J. Microsc. 12437 
Keyser DF 1979 Introduction to analytical electron microscopy (eds) J J Hren, J I Goldstein and D C Joy (New York: Plenum Press) p. 199

Oppolzer H and Knauer V 1979 Scanning electron microscopy (ed) O Johari (Chicago: SEM Inc) 111

Philibert J and Tixier R $1968 \mathrm{~J}$. Appl. Phy's. 1685

Porter D A and Westengen H 1981 Quantitative microanalysis with high spatial resolution (London: Metals Society) p. 94

Schreiber T P and Wims A M 1981 Ultramicroscopy 6323

Tixier R and Philibert J 1969 Proc. 5th int. conf. on x-ray optics and microanalysis (eds) G Molleustedt and K H Garukler (Berlin: Springer Verlag) p. 180

Williams P M 1980 Chem. Phys. Solid Sur. 884

Woods J, Williams D B and Goldstein J I 1981 Quantitative microanalysis with high spatial resolution (London: The Metals Society) p. 24

Zaluzec N J 1979 Introduction to analytical electron microscopy (eds) J J Hren, J I Goldstein and D C Joy (New York: Plenum) p. 121 